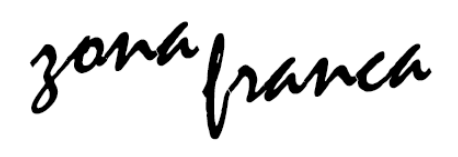

\title{
Corpos nas ruas no 8M (2019): Afro peruanas, Afro argentinas e Afro \\ brasileiras em movimento
}

Joselina da Silva*

\section{Resumen}

La calle ha sido tradicionalmente el lugar de reivindicaciones de las mujeres organizadas en movimientos sociales en toda América Latina. En Brasil, las mujeres negras han conquistado este espacio hace algunas décadas, sin embargo, fue a partir de 2015 que empezaron a tener lugar marchas específicas de las afrodescendientes relacionadas con la conmemoración del día de la mujer negra de América Latina y el Caribe, celebrado el 25 de julio. También contamos con experiencias más recientes que son extremadamente representativas: manifestaciones organizadas por mujeres negras en Argentina y el Perú dentro de la marcha feminista tradicional. Se trata de ocasiones en que el pluralismo del movimiento se hace presente, permitiendo así que se escuche el sinfín de voces que lo componen en un tono unificador todavía naciente en su universo. Este texto forma parte del proyecto de investigación actual de postdoctorado (2018/2019) del Departamento de Ciencias Sociales en la Pontifica Universidad Católica del Perú, bajo el título INTERSECCIONALIDAD ENTRE GÉNERO Y RAZA: EL MOVIMIENTO DE MUJERES NEGRAS EN AMÉRICA AFRO LATINA (PERÚ, URUGUAY Y ARGENTINA).

Palabras claves: Marchas - Mujeres negras- Movimiento social Afrodescendientes - Feminismo

* Doutorado em Ciências Sociais. Coordena o N’BLAC (Núcleo Brasileiro, Latino Americano e Caribenho de Estudos em Relações Raciais, Gênero e Movimentos Sociais), certificado pelo CNPQ. Orienta mestrado e doutorado no Programa de Pós-graduação em Educação da Universidade Federal do Ceará (UFC) e no Programa de Pós-Graduação em Educação, Contextos Contemporâneos e Demandas Populares (PPGEduc), da UFRRJ. É professora associada da Universidade Federal Rural do Rio de Janeiro (UFRRJ).Pos doutoranda pela Pontifícia Universidade Católica do Peru (PUCP). Contacto: joselinajo@yahoo.com.br

Da Silva, Joselina. "Corpos nas ruas no 8M (2019): Afro peruanas, Afro argentinas e Afro brasileiras em movimento" en Zona Franca. Revista del Centro de estudios Interdisciplinario sobre las Mujeres, y de la Maestría poder y sociedad desde la problemática de Género, №27, 2019 pp.288-309. ISSN, 2545-6504 Recibido: 30 de junio 2019; Aceptado: 11 de noviembre 2019

Revista Zona Franca- Centro de estudios interdisciplinario sobre las mujeres (CEIM)- Maestría poder y sociedad desde la problemática de género (MG), Rosario, Argentina. ISSN, 2545-6504 http://zonafranca.unr.edu.ar/index.php/ZonaFranca| Numero 27 (2019). 


\title{
Bodies on the streets in 8M (2019): Afroperuvians, Afroargentinas and Afrobrasilians in moviment
}

\begin{abstract}
Specially in Latin America the streets have tradicionally been the place where socially organized women's movements make their claims. In Brasil, for some decades those oportunities have been attained by black women, and since 2015 afrodecendant women's specific marches have also been taking place inspired by the july 25Th the afrolatinomerican and afrocaribean women's day. With more recent experiences and also representatively important there have been elaborated manifestations - inside the tradicional feminist marches - by black women in Argentina and Peru. Those are the occasions when the pluralism of the moviment is made visible and numerous voices that are part of it and some times are muted in na unified way become finally audible. This article is part of a pos doctoral research (2018/2019) being developed at the Pontifícia Universidade Católica do Peru, under the Social Sciences Department named: INTERSECTIONALITY between gender and race: black women's moviment in Afrolatino América (PERU, URUGUAI and ARGENTINA).
\end{abstract}

Key words: Marches - Black women- social movement - Afrodescendants - Feminism

\section{Introdução}

A rua tem sido tradicionalmente o lugar de reivindicação das mulheres organizadas, nos movimentos sociais, notadamente na América Latina. A revista Isis Internacional vol. V de junho de 1986 propicia uma rápida recopilação daqueles que - segundo o alcance de seu olhar - foram notáveis acontecimentos mundiais referentes ao feminismo, num período de quinze anos (1975-1980). De acordo com a referida cronologia, temos então que o Peru, em 1973 protagoniza um dos primeiros protestos de rua, quando feministas se posicionam frente ao Hotel Sheraton numa ação contra os concursos de beleza (pag. 97).

Dois anos mais tarde, foi a vez das mexicanas ocuparem as vias públicas em várias ocasiões em atenção ao "Ano Internacional da Mulher", declarado pelas Nações Unidas, como abertura do decênio das mulheres. Pouco mais adiante, em

Revista Zona Franca- Centro de estudios interdisciplinario sobre las mujeres (CEIM)- Maestría poder y sociedad desde la problemática de género (MG), Rosario, Argentina. ISSN, 2545-6504 http://zonafranca.unr.edu.ar/index.php/ZonaFranca| Numero 27 (2019). 
1977, ainda a partir da cronologia da referida revista, as Mães da Praça de Maio grupo criado naquele ano - transformaram em pauta internacional a luta em favor dos desaparecidos políticos vitimados pela ditadura militar, na Argentina. Ainda naquele mesmo período, as mexicanas, uma vez mais, saíram às ruas. Desta vez para marchar contra o machismo (pá.99). No ano seguinte, o tema da legalização do aborto, tomou palco numa representação teatral em frente a um monumento público da capital do México.

Ainda, de acordo com a breve periodização da revista Isis Internacional, para a década da mulher, as mexicanas através do "movimento Nacional de Mujeres" realizam uma marcha de enlutadas pelas vítimas de abortos clandestinos (pag. 101). Também no Chile as mulheres se organizaram tendo as ruas como referência, em 1980. Ali, cerca de cento e cinquenta mulheres foram detidas por estarem num ato pelo dia oito de março. Por sua vez, as peruanas - ainda dando continuidade à vocação de ter nas ruas o instrumental sonoro para fazer reverberar pensamentos e denúncias - organizaram uma marcha de mulheres de luto, em protesto ao assassinato de duas argentinas do movimento motoneros.

Assim, nos informa a publicação que em 1980, foi a vez do Brasil - através das mulheres organizadas - realizar um protesto, no Rio de Janeiro, mediante a prisão de mulheres em razão de haverem praticado o aborto. Outro movimento importante foi a campanha "não mais violência", que propiciou a realização de atos públicos em diversas cidades da América Latina, durante o ano de 1981. Um evento que também acabou por estimular atos de protesto onde ocorria, foram os concursos Miss Universo. Em 1982 foi a vez das peruanas liderarem este movimento. Por esta razão, sofreram agressões e forma arrastadas pelas forças policiais. Também duramente reprimidas foram as chilenas, naquele mesmo ano, ao organizar um ato público na Praça da igreja San Francisco, por ocasião do 8 de março.

Revista Zona Franca- Centro de estudios interdisciplinario sobre las mujeres (CEIM)- Maestría poder y sociedad desde la problemática de género (MG), Rosario, Argentina. ISSN, 2545-6504 http://zonafranca.unr.edu.ar/index.php/ZonaFranca| Numero 27 (2019). 
Insistimos aqui em trazer - embora brevemente - uma parte da longa cronologia apresentada pela publicação, objetivando demonstrar que na história recente do movimento de mulheres na região. Demonstrações públicas são uma das estratégias adotadas - por feministas ou não- como forma de visibilizar as opressões das quais tem disso vítimas as mulheres em diferentes países. Ao mesmo tempo, historicamente o movimento feminista tem utilizado as marchas do 8 de março como tribuna referencial para divulgar e debater publicamente suas agendas, denúncias e demandas.

São ocasiões em que o pluralismo do movimento se faz presente, tornando audíveis as inúmeras vozes que o compõem e que algumas vezes são emudecidas num modo unificador, ainda reinante em seu universo. Por outro lado, há uma vasta a literatura, na América Latina seja elaborada no ambiente acadêmico ou através dos discursos do movimento das afrodescendentes. Esta aponta uma tensão entre o feminismo da região - denominado por algumas autoras, como feminismo hegemônico - e as organizações de mulheres negras. Neste sentido, o documento elaborado no transcurso do VII Encuentro Feminista Latino Americano y del Caribe, nos dá uma aproximação do que denuncia o movimento de mulheres negras:

\footnotetext{
"Las mujeres negras, participantes de este encuentro, reunidas em um taller improvisado tenemos las seguientes consideraciones para las cuales pedimos la reflexión del conjunto delas compañeras em este Encuentro: 1) Siendo este el VII Encuentro Feminista Latinoamericano y del Caribe, consideramos um retorceso que se haya omitido em las discusiones el tema "Raza y Etnia"; 2) Nesse sentido, contrario a la dinámica de los otros encuentros, nos indignamos por no estar incluído em el programa oficial del Encuentro um taller específico sobre o tema...Este é un desafío para el movimento feminista em su totalidad assumir como agenda común la cuestión de las mujeres negras, sustentada em el respeto a la diversidade y pluralidade, princípios éticos feministas fundamentais (Mauleón, 1998, 78)".
}

Revista Zona Franca- Centro de estudios interdisciplinario sobre las mujeres (CEIM)- Maestría poder y sociedad desde la problemática de género (MG), Rosario, Argentina. ISSN, 2545-6504 http://zonafranca.unr.edu.ar/index.php/ZonaFrancal Numero 27 (2019). 
Note-se que este documento foi apresentado quatro anos após o primeiro encontro de mulheres afrolatinoamericanas e afrocaribenhas, celebrado, na República Dominicana, em 1992. O que demonstra a cegueira do movimento feminista, daquela década em perceber a crescente e vital organização das mulheres negras na região.

Tal olhar de descontentamento é denunciado também hodiernamente por ativistas negras em diferentes países. No Brasil, por exemplo, esta dificuldade de Inserção enseja a oportunidade para que Sueli Carneiro produza seu clássico texto: Enegrecer o feminismo (Carneiro, 2003), onde a refere-se à nova ótica a ser empreendida pelo feminismo, com a entrada das mulheres negras organizadas trazendo em seu bojo diferenciadas perspectivas a serem consideradas como forma de reconhecer suas agendas e lutas específicas. É desse lugar, que podemos entender que décadas antes Lélia Gonzales, denunciasse a ausência de preocupação do feminismo coma as questões relativas ao racismo que se abate sobre as mulheres negras. Intitulava a esta atitude de "racismo por omissão" (Gonzales, 1988: 24)

Ao mesmo tempo, historicamente o movimento feminista tem utilizado as marchas do 8 de março como tribuna referencial para divulgar e debater publicamente suas agendas, denúncias e demandas. Eventos que ocorrem em diversas partes do mundo, são ocasiões em que o pluralismo do movimento se faz presente, tornando audíveis as inúmeras agendas e diversidades de vozes que 0 compõem e que algumas vezes são emudecidas num modo unificador - ainda reinante- em seu universo.

No Brasil, há algumas décadas, estas oportunidades tem sido conquistadas pelas mulheres negras, embora a partir de 2015, marchas específicas das afrodescendentes também têm ocorrido, por ocasião do 25 de julho, dia da mulher negra da América Latina e do Caribe. Com experiências mais recentes, porém 
importantemente representativas, temos manifestações elaboradas - no interior da marcha tradicional do feminismo -por mulheres negras, na Argentina e no Peru.

Nestes exemplares, ocorreram performances - notadamente em 2019 - onde símbolos africanizados em diáspora (turbantes, tambores e ritmos) conduzem, as mulheres negras, sob os olhares e ouvidos de uma plateia ainda insistente em invisibilizar suas existências. Motivadas por uma narrativa nacional de branquidade ou mestiçagem. Situação que provoca corpos submetidos à hipersexualização, ao toque indesejado e ao não direito de estar ou ser. Neste sentido, se expressa Eliza Pfluger, afro feminista peruana, durante a marcha dos anos que estamos analisando aqui:

Creo que es muy complejo esto de volver a mirarnos cada una desde la individualidad y desde las colectividades que representamos. No hay, hasta ahora, mujeres feministas peruanas que se nombren desde su blanquitud y que la reconozcan como parte de un privilegio que van a tener frente a otras mujeres. No es decirles que renuncien a su blanquitud, pero sí estar alertas, que sean conscientes de los privilegios que les da su ser blancas, ser heterosexuales, tener título universitario, su apellido, su clase... Si tu discurso va a seguir homogeneizando a las demás mujeres e invisibilizando a otras, mantienes esta lógica bien hegemónica que solo presenta una sola historia del feminismo. Necesitamos que las feministas se miren, se enuncien desde todas esas interseccionalidades (así te haya tocado tener las más privilegiadas o no). Pero te toca reconocerlas para desde ahí, reconocer qué está en escena a través de tu cuerpo y tu palabra!.

Um grupo de mais de cem mulheres negras - no Rio de Janeiro, em 2019 onde sessenta portavam um turbante dourado assomou-se à marcha feminista já no decorrer do percurso. As afrodescendentes, lideradas pelas integrantes do Fórum Estadual de Mulheres Negras, marcaram sua concentração em lugar diferente daquele tradicionalmente escolhido pela marcha oficial: a Igreja da

I Fonte: https://www.mujeresdelsur-afm.org/peru-america-latina-va-a-ser-negra-y-feminista. Acessado em maio de 2019.

Revista Zona Franca- Centro de estudios interdisciplinario sobre las mujeres (CEIM)- Maestría poder y sociedad desde la problemática de género (MG), Rosario, Argentina. ISSN, 2545-6504 http://zonafranca.unr.edu.ar/index.php/ZonaFrancal Numero 27 (2019). 
Candelária, no centro da cidade. Enquanto aguardavam ao longo de todo o percurso, foram embaladas por aparelhos de som, músicas afro e palavras de ordem.

Neste sentido, este artigo se pilarisa a partir da observação através da participação das mulheres negras nas marchas do oito de março de 2019. Nos interessa o processo sócio organizativo das afrodescendentes nestes três estados-nação, com histórias tão dispares em sua formação. Embora, guardem grandes proximidades quando nos voltamos a analisar as políticas de incentivo à mestiçagem e ao branqueamento, ali institucionalizadas, como veremos adiante.

\section{Quando raça e racismo falam nos estados nacionais}

Pensar alguns dos estados nacionais latino americanos - Argentina, Peru e Brasil - nos conduz a observar a influência das teorias raciais, sobretudo no seu capítulo sobre mestiçagem. Neste entendimento, observamos Karl Mosna, no prefácio de Andrews (2007) quando afirma que há muita similitude entre o que ocorre nos países colonizados pela Espanha e Portugal no que concerne à "história racial" da região.

O autor ainda acentua que alguns aspectos da racialidade brasileira - tidos como manifestos apenas em solo nacional- são tão presentes na região como um todo. Refere-se, por exemplo, ao mito da democracia racial e a não aceitação, por partes de setores brancos da sociedade, do racismo que não diz seu nome. Este, intitulado por Karl Mosna de "racismo informal". No tocante aos argentinos, a retórica do Estado Nação era o mito da "Argentina Branca". O país se colocava hierarquicamente superior em termos raciais na região, ao comparar-se com os demais.

Aguirre (2000), refletindo sobre o racismo no Peru, afirma esta situação tem origem no período colonial momento em que foram constituídos os pilares ideológicos onde se assentavam a opressão contra negros e índios no país. A

Revista Zona Franca- Centro de estudios interdisciplinario sobre las mujeres (CEIM)- Maestría poder y sociedad desde la problemática de género (MG), Rosario, Argentina. ISSN, 2545-6504 http://zonafranca.unr.edu.ar/index.php/ZonaFrancal Numero 27 (2019). 
partir dali índios e negros sofreram o processo de exclusão do projeto nacional criollo, e por conseguinte, discursos foram construídos aprofundando o racismo.

Portanto, a legitimação dos estados nacionais Latino Americanos em fins do século XIX e início do XX, foi fartamente influenciada pelos pensadores europeus elaboradores do racismo cientifico. No caso das Américas de colonização espanhola, o índio era o foco principal de preocupação subsidiada pelo darwinismo social. Para aqueles teóricos e ou políticos a barbárie estava presente no legado deixado por índios, mestiços e negros.

Acreditava-se que só uma ajuda externa podia salvar os diversos estados nacionais. Assim os imigrantes europeus contribuíam com mão de obra- eram vistos como expertos em diferentes áreas- mas também biologicamente iam ajudando a diminuir a presença do sangue condenado. Produzindo, assim, mestiços cada vez mais claros até que embranquecessem a população. Era o branqueamento salvador. Observando os estados que ora abordamos, neste projeto, temos que a Argentina e Uruguai tiveram uma expressiva imigração europeia em fins do século XIX e início do século XX. O

Peru por sua vez, teve uma expressiva uma imigração chinesa. Essas imigrações contribuíram para retirar os negros do estado laboral. Podemos então afiançar, apoiados na literatura acadêmica - lida até o momento - que um dos fatores que une os três países é o ideário da imigração europeia. A mesma era percebida como esperança aniquiladora das raças não brancas. Era o prognóstico da melhoria das raças, uma vez que enfatiza e valora o branqueamento como um desejo a ser perseguido. Lembra Agirre (2000) que esta é uma pratica em grande parte da América Latina, portanto, não apenas uma especificidade peruana.

$\mathrm{Na}$ Argentina, por sua vez, construiu-se a retorica do estado, onde a branquidade, desde o século XIX, foi e tem sido exaltada. Assim, o país consagra o discurso dominante vendo-se como branco, europeu, moderno, racional e católico (Frigerio e Lamborghini, 2009). Neste sentido, quaisquer outras

Revista Zona Franca- Centro de estudios interdisciplinario sobre las mujeres (CEIM)- Maestría poder y sociedad desde la problemática de género (MG), Rosario, Argentina. ISSN, 2545-6504 http://zonafranca.unr.edu.ar/index.php/ZonaFranca| Numero 27 (2019). 
identidades raciais são removidas. Se por acaso são citados, imediatamente são posicionados de forma longínqua (seja no tempo ou no território).

Guimarães (1999) nos lembra da constante tentativa, no Brasil, de negação da ideia e conceito de racialidade. Construído, o país, como uma democracia racial, notadamente após os estudos de Gilberto Freire, ainda hoje, temos adventos de racismos nas diversas esferas sociais. Assim, podemos surpreender diferentes manifestações de racismo, no território nacional, tais como institucional, religioso, do cotidiano ambiental e vários outros.

\section{Quando o corpo fala}

Le Breton (2006) apresenta o corpo como locus de construção social e como tal, depositário de imaginários e representações sociais e culturais. Para o autor, a corporeidade humana perpassa a vida cotidiana no seu ambiente envolvendo seus afazeres mais simples ou mais complexos.

"Do corpo nascem e se propagam as significações que fundamentam a existência individual e coletiva; ele é o eixo da relação com o mundo, o lugar e o tempo nos quais a existência toma forma, através da fisionomia singular de um ator. Através do corpo, o homem apropria-se da substância de sua vida traduzindo-a para os outros, servindo-se dos sistema simbólicos que compartilha com os membros da comunidade (Le Breton, 2006:7)".

O autor, aqui estudado, nos indica que não há existência humana sem a presença corporal. A partir do corpo, toda uma plêiade de significados, valores e símbolos são estabelecidos e compartilhados socialmente com o mundo ao redor. Destarte, a partir do corpo, são recebidos ou emitidos sentidos que vão desde a infância à idade adulta. Por outro lado, lembra o autor, que os aprendizados corporais - gestos, mímicas, socializações - adquiridos nos primeiros anos de vida não são fixos e podem modelar-se socialmente ao longo de sua existência.

Revista Zona Franca- Centro de estudios interdisciplinario sobre las mujeres (CEIM)- Maestría poder y sociedad desde la problemática de género (MG), Rosario, Argentina. ISSN, 2545-6504 http://zonafranca.unr.edu.ar/index.php/ZonaFranca| Numero 27 (2019). 
As peruanas se prepararam por cerca de dois meses com ensaios duas vezes por semana, para estarem em marcha. Músicas foram elaboradas, onde novas letras aplicadas a canções tradicionais afroperuanas deram ânimo durante o cortejo. Aulas de percussão, de instrumentos ancestrais da cultura negra, danças e ritmos que as embalariam durante a apresentação nas ruas da cidade, passaram a ser meticulosamente ensinadas e aprendidas pelo grupo de cerca de sessenta mulheres.

Assim sendo, ainda nos referindo a Le Breton (2006), todas as manifestações desempenhadas pelo corpo, só podem ser interpretadas quando analisadas dialogicamente num determinado contexto sócio cultural. Seguindo nesta linha de análise podemos entender o que nos diz Denise Braz", ao se referir ao uso dos turbantes, pelas mulheres negras, na marcha do 8 de março, em Buenos Aires.

A gente acredita que o nosso corpo é um corpo político. É um corpo que fala muito e estando juntas com turbantes é uma maneira de visibilizar ainda mais esse corpo político, numa marcha que é majoritariamente branca. A gente quer incomodar para o bem (Denise Braz, março 2019) ${ }^{\prime \prime \prime}$.

Por conseguinte, à luz de Le Breton (2006), o corpo será estranho ou familiar a um grupo a partir da gama de símbolos e significados reconhecidos ou não por um determinado grupo social, região, cultura, bem como o período sócio histórico em que esteja localizado. Desta froma, o autor questiona a naturalização do gesto ou sensações corpóreas. Já que estes são resultantes do lugar social ocupado por cada corpo.

"Denise Braz é licenciada em Letras pela Pontifícia Universidade Católica de Minas Gerais. Mestre em antropología social pela Universidade de Buenos Aires. É ativista e feminista afrolatinoamericana. É integrante da área de gênero do coletivo afro Comissão Organizadora do Día 8 de Novembre, da Revista Amazonas e é representante de Afrofeminas (Espanha) em Buenos Aires.

III Denise Brasão

Revista Zona Franca- Centro de estudios interdisciplinario sobre las mujeres (CEIM)- Maestría poder y sociedad desde la problemática de género (MG), Rosario, Argentina. ISSN, 2545-6504 http://zonafranca.unr.edu.ar/index.php/ZonaFrancal Numero 27 (2019). 
Tradicionalmente, os corpos negros tem ocupado lugar de desprestígio nas sociedades latino americanas. Se fizermos uma análise interseccional veremos que este quadro se agudiza quando o corpo é de uma mulher negra, como diz Monica Carrillo Zegarra, no livro Insumissas (2010), onde compartilha experiências de opressão nas ruas de Lima, no Peru.

"Llego ao mercado de Jesus Maria. Es um espacio abierto donde hay tiendas dispersas en diversas calles. Mientras camino diviso a dos hombres que vienen hacia mi dirección. Se detienen ante mí, impidiéndome el paso “¿Eres africana?”, pregunta uno. “El doctor me dijo que las negras como tú son la mejor medicina porque saben hacer felices a los hombres". Comenta....Ya estaba de vuelta camino a casa. Un auto me toca la bocina desde lejos. Yo tomo la acerra en sentido contra el tráfico para que no me siga. Pero da la vuelta a la manzana y me encuentra en el cruze de las calles.... Me sigue. Se detiene e disse “¿Quieres que te lleve?”. Es la undécima persona que me agrede (Zegarra, 2010, págs. 117-118)".

É deste lugar, do qual na fala Zegarra (2010) que podemos voltar a Le Breton (2006) quando nos informa que é longa a história das ciências no seu capítulo voltado aos estudos do corpo. Naqueles primórdios, a biologização ocupou lugar de primazia com os estudos de degenerescência dos corpos não brancos ou as teorias antropormórficas onde crâneos não europeus eram imediatamente posicionados numa escala de inferiorização.

Assim, podemos entender a presença organizada das mulheres negras reunidas em grupos nos percursos das marchas, nos três países, aqui abordados. Seus corpos carregam mensagens político culturais pela mera presença naquele cortejo de mulheres (de diferentes raças e etnias) posicionando-se contra diversas opressões, como nos diz Denise Brasão: Na marcha, tem algumas que nem pano tem. A gente leva o pano... É fazer com que ela sinta orgulho de si mesma e que recupere esse orgulho. Ou ainda como diz elisa Pfluger, do Peru:

Revista Zona Franca- Centro de estudios interdisciplinario sobre las mujeres (CEIM)- Maestría poder y sociedad desde la problemática de género (MG), Rosario, Argentina. ISSN, 2545-6504 http://zonafranca.unr.edu.ar/index.php/ZonaFrancal Numero 27 (2019). 
"Nuestra aparición con instrumentos fue parte de un acto performativo de reconexión musical. Reivindicamos que nuestra apuesta política y en la calle puede estar musicalizada... Nuestros cuerpos, solo al estar presentes, ya dicen mucho: son resistencia. Si a eso le agregamos este ejercicio de la parte rica, del buen sonido... La música dentro de los pueblos afrodescendientes siempre ha sido un espacio, una plataforma, una herramienta de reivindicación, de denuncia, de crónica, de generar historiografía. No va a ser solo un entretenimiento sino una apuesta política desde las mujeres negras"'v .

Desta forma, ao nos balizarmos por Le Breton (2006), a corporeidade possui em si, uma lógica social e cultural. Logo, não ocorre de maneira espontânea e unicamente individual. Desta maneira, o corpo será estranho ou familiar a um grupo, baseados numa gama de símbolos e diferentes significados a partir dos quais se estruturam as existências individuais e coletivas.

"El Día 8 Marzo del 2019 fue, es una fecha de vital importancia para las mujeres Afroactivistas de Presencia y Palabra. La música y danza son nuestra resistencia ante el sistema patriarcal y racista. Viví la emoción de marchar con dos mis hijas, que muchas veces no entendieron mi activismo y ahora hermanadas en una sola voz, hermanadas junto a otras mujeres negras, compañeras del proceso. Abuelas y nietas, madres e hijas, tias y sobrinas, hermanas y amigas en una sola voz, guiadas por el espíritu de nuestras Ancestras cantábamos" Somos las hijas de ésas esclavas que nunca pudiste matar". Fue impactante éste grito de protesta en las calles de lima, mujeres negras silenciadas por la sociedad, racismo, machismo expresando unidas sus voces.Un sueño hecho realidad, siempre habia anhelado un bloque único de mujeres Afroperuanas ....mi sueño se hizo realidad. Es de suma importancia para nuestro proceso esta unión intergeneracional."

Ela nos fala em desfilar em família. Assim, os corpos coletivizados tomam lugar de maior representação social e política. Não apenas para os de fora - que

IV Fonte: https://www.mujeresdelsur-afm.org/peru-america-latina-va-a-ser-negra-y-feminista/ Acessado em maio, 2019.

Revista Zona Franca- Centro de estudios interdisciplinario sobre las mujeres (CEIM)- Maestría poder y sociedad desde la problemática de género (MG), Rosario, Argentina. ISSN, 2545-6504 http://zonafranca.unr.edu.ar/index.php/ZonaFrancal Numero 27 (2019). 
participam da marca ou aos que a observam a partir das janelas e calçadas como também, para os de dentro: os do seio familiar. Forma-se, portanto, uma tríplice identidade: mulher, negra e em família. Nos referimos então, à uma identidade coletiva, onde está se constitui a partir de um resgate de história e autenticidade, ao lado da construção de um imaginário positivo baseado numa auto estima e na reescrita de uma historiografia colonial (Munanga, 2006).

Desta forma, Nachi e as mulheres de sua família - todas negras - como peruanas criadas numa sociedade em que os negros são o 'outro nacional”, após se deixarem expor aos momentos de reconstrução identitária liderado pelo movimento de mulheres negras, - neste caso o grupo Presencya y Palabra reconfiguram-se para a marcha e em sus cotidianos. Transformam-se em novas mulheres afrodescendentes ou afroperuanas.

\section{Adornos e indumentárias falam}

Mary Ellen Roach e Joanne Bubolz Eicher no texto Language of Personal Adornment (2011) nos lembram que todas as sociedades tem como caraterística os adornos pessoais. Assim, o ato de vestir-se pode ser - para muitas pessoasuma ação estética e está por sua vez é sempre uma expressão e uma fala. Neste caminho, a comunicação daí derivada, através do adorno, pode ser um ato individual, mas passa a ter sentido somente quando relacionado de forma coletiva.

Portanto, ainda à luz das autoras, o ato estético surge a partir do que é aprendido de uma comunidade. Este, contudo, não se constitui do nada. É socialmente construído, a partir do desenvolvimento tecnológico, dos recursos ambientais e os padrões culturais, da época em questão. Todos responsáveis pela definição do que é fino e belo. Estas adjetivações podem representar múltiplos significados em diferentes sociedades.

Nesta mesma direção, os adornos concebem diferentes missivas a partir de si. Para estas autoras, podem representar uma experiência estética. Neste caso,

Revista Zona Franca- Centro de estudios interdisciplinario sobre las mujeres (CEIM)- Maestría poder y sociedad desde la problemática de género (MG), Rosario, Argentina. ISSN, 2545-6504 http://zonafranca.unr.edu.ar/index.php/ZonaFranca| Numero 27 (2019). 
se expressa através do humor (bom ou mal) por diferenciar-se dos demais. Um outro lugar de representação do adorno é a definição de lugar social, de ascensão social, de status econômico, de símbolo político, como condição mágico-religiosa e como facilitador de rituais sociais. Pode também se anunciar como aquele que robustece a fé, costumes, valores e se fazer presente em momentos de lazer e como símbolo sexual. Portanto, ao inquirirmos uma das realizadoras dos turbantes, na Marcha de Buenos Aires, Denise Brasão, assim nos contesta:

A questão dos turbantes é porque é um símbolo muito forte para as mulheres negras. O turbante não faz parte somente da cultura afrodescendente e também não é adorno especificamente feminino. Os homens também usam turbantes, em outras culturas.... Mas, o turbante para a mulher negra talvez seja o símbolo mais forte de auto conhecimento, de auto identificação e de orgulho negro, de orgulho de si. Quando uma mulher negra está com um turbante - aqui em Buenos Aires, especificamente - a gente percebe um olhar de incomodo, muitas vezes. O turbante incomoda mais que uma trança, um colar, uma maquiagem afro. (Denise Braz, março 2019).

De todas as possiblidades de representação social do uso dos adornos, nos interessa aqui, aquela, que as autoras denominam de utilização como símbolo político. Assim sendo, vale que lembremos que adornos podem representar a posição hierárquica de poder, como o caso das medalhas no peito ou braço dos militares, só para citar algumas. Podem significar também a afiliação a um grupo político ou partidário, como o uso de camisetas ou bonés vermelhos pelos integrantes ou simpatizantes de partidos de esquerdav ${ }^{\mathrm{V}}$. No caso das mulheres negras, nas marchas do Rio de Janeiro e de Buenos Aires, os turbantes tiveram essa representação, como nos diz Clatia Vieira, sobre a Marcha do Rio de Janeiro.

$\checkmark$ Durante a acirrada campanha eleitoral para presidente da República, em 2018, as camisetas e bonés verdes e amarelos - utilizados anos antes para comemorar a participação do Brasil, na Copa do Mundo de futebol - voltaram às ruas, desta vez para demarcar apoio político na campanha do candidato de direita. De elemento de patriotismo esportivo se transmutaram em representantes do patriotismo partidário de extrema direita.

Revista Zona Franca- Centro de estudios interdisciplinario sobre las mujeres (CEIM)- Maestría poder y sociedad desde la problemática de género (MG), Rosario, Argentina. ISSN, 2545-6504 http://zonafranca.unr.edu.ar/index.php/ZonaFrancal Numero 27 (2019). 
A gente não tinha dinheiro para fazer camisas. Então vamos pensar em turbante. A Jô (Josina) foi procurar um tecido. Inicialmente faríamos quarenta turbantes. Ela foi muito feliz. Encontrou um tecido super maravilhoso, lindo, que grita. Que qualquer um avistava nossas cabeças a quilômetros. Foi um processo bonito, uma amarrando a outra.. aí, nós tínhamos uma coisa muito alegre, cantamos o samba da mangueira $^{\mathrm{Vl}}$.(Clatia Vieira, maio, 2019)

Os adornos podem estar presentes em diversas gerações, passando de um a outro grupo de poder. Assim, além das roupas utilizadas por representantes políticos, religiosos, culturais ou policiais, os adornos (botons, distintivos, bonés, braçadeiras, camisetas, entre outros) podem significar a afiliação ou apoio a um determinado grupo ou liderança, ideologia, religião ou cultura. Portanto, adornos, além de sua função decorativa, podem ser seriamente adotados comunicando mensagens as mais variadas, incluído poder e hierarquia. Neste sentido, as mulheres negras em marcha, em Lima, na mesma data, envergavam camisetas amarelas com frases: a vida das mulheres negras importam. O que remete ao atual movimento internacional, iniciado nos Estados Unidos: Black lives matter. Por conseguinte, transformam-se em mulheres em luta, conectadas com a diáspora.

Nas mãos, traziam faixas com desenhos de búzios que lembram as tradições religiosas e culturais do continente africano. Ao mesmo tempo, seguiam embaladas pelos tambores, caixas e queixadas de burro.

La idea era empezar un proceso que tomara esos elementos: reivindicación desde el arte afroperuano, arengas, música creada por Victoria Santa Cruz; retomar y adaptar música creada en el Perú, usando

VI Clatia Vieira - Bacharel em Direito; Vice presidenta do Sindfilantrópicas; Membro da Coordenação executiva Nacional do Fórum Nacional de Mulheres Negras; membra do Colegiada do Fórum Permanente de Dialogo das Mulheres Negras com Alerj; Integrante da Coordenação Ampliada do Fórum Estadual de Mulheres Negras de Mulheres Negras RJ. Integrante do Comitê impulsor da 1a. Marcha Nacional de Mulheres Negras/2015; Integrante da Coordenação das Marchas das Mulheres Negras do RJ.

Revista Zona Franca- Centro de estudios interdisciplinario sobre las mujeres (CEIM)- Maestría poder y sociedad desde la problemática de género (MG), Rosario, Argentina. ISSN, 2545-6504 http://zonafranca.unr.edu.ar/index.php/ZonaFrancal Numero 27 (2019). 
instrumentos del pueblo afroperuano. Con Rocío Muñoz, Tatiana Espinoza y las demás compañeras de PyP $\mathrm{P}^{\mathrm{VII}}$ nos preguntamos "¿Qué planteamos ahora?". Quisimos hacer un proceso de afro-artivismo, ir conociéndonos para respondernos estas preguntas: ¿Qué pensamos de las marchas? ¿Por qué las mujeres afro no hemos estado antes en las marchas? ¿Qué queremos? $Y$ en esa última pregunta casi todas coincidíamos en que no queríamos hacer la marcha dura y la arenga dura. Si hay algo que nosotras tenemos es el tema del trabajo rítmico pero, al mismo tiempo, no queríamos que se desvirtúe en "las negras siempre bailando por bailar" ${ }^{\prime \prime I I I . ~}$

Seguindo nesta linha de reflexão, temos que entre os Yorubá da Nigéria e aqueles do Benin, segundo HJ Drewal (1979), a posição social da pessoa é expressa de forma referencial através da roupa. A profissão, formação, status e bem-estar são fatores que podem ser determinados pelo que se está trajando. Portanto, segundo o autor, a roupa expressa, para o exterior, uma comunicação sobre o lugar de ocupação de responsabilidade da pessoa num grupo mais amplo. Nas Américas, entre os vários símbolos de pertencimento à uma africanidade, o turbante se destaca. Daí, seu uso político cultural nas marchas, como afirmação de identidade política das mulheres negras, como em Buenos Aires:

Olha essa mulheres sentem orgulho do jeito que elas são e da cultura que tem. Há muitas mulheres que colocam o turbante pela primeira vez, na marcha. A gente coloca o turbante na caça das companheiras. Tem uma foto de $(A)$ colocando o turbante em (B). Ela nunca mais tirou o turbante da cabeça. Ela nunca havia usado um turbante. É essa questão de ancestralidade. Devolver essa ancestralidade. Devolver o poder a essa companheira (Denise Braz, março 2019) (Denise Braz, março 2019).

Em consequência, retornando aos yorubás, tanto o lado estético quanto o seu simbolismo determinam o papel social, bem como as responsabilidades de

VII PyP - Presencia y Palavra, grupo feminista de afroperuanas.

VIII Fonte: Perú: América Latina va a ser negra y feminista. https://www.mujeresdelsur-afm.org/peruamerica-latina-va-a-ser-negra-y-feminista

Revista Zona Franca- Centro de estudios interdisciplinario sobre las mujeres (CEIM)- Maestría poder y sociedad desde la problemática de género (MG), Rosario, Argentina. ISSN, 2545-6504 http://zonafranca.unr.edu.ar/index.php/ZonaFrancal Numero 27 (2019). 
cada um na hierarquia social do grupo. Os adornos (contas, braceletes e turbantes, ente outros) são marcadores referenciais nos momentos de culto, como também, em ocasiões sociais, tais como casamentos, ou cerimônias de nomeação, por exemplo. É deste lugar que nos fala Josina Maria da Cunha, do Rio de Janeiro.

Eu falo de turbante. E para poder falar de turbante, eu falo de Ori, que é cabeça, que é a nossa conexão dos pés a cabeça, com o universo. Com o cosmos. Sem falar de Ori eu não consigo falar de turbante. E dentro de nossas marchas, nós temos uma série de turbantes, de lalorixás e de turbanteiras que amarram suas cabeças (Josina. Rio de Janeiro, Maio, 2019) ${ }^{\mathrm{IX}}$.

Por conseguinte, no âmbito da diáspora africana, os turbantes tem contraído representação religiosa, política e identitária. Na primeira, é utulizado em função ritualística das religiões de matriz africanas, como um protetor da cabeça, durante os momentos sagrados dos cultos. Neste ambiente, cores formas de amarração, tamanhos e tipos dos tecidos dispõem o (a) usuário (a) em lugares hierárquicos e em posições diversas na adoração ritualística. Este seguinte relato, muito se aproxima ao já reportado aqui, a respeito da representação social dos adornos e das roupas, a partir dos estudos de HJ Drewal (1979).

Neste ano de 2019, nós resolvemos fazer um grupo maciço de mulheres negras dentro da marcha do 8 de março junto com as mulheres feminista de todas as áreas. E a nossa identidade a gente resolveu que seria o nosso Ori. $O$ que nos remeteu à nossa ancestralidade, à nossa conexão com a África, às cores douradas de Oxum. ... A gente queria marcar a nossa identidade afro brasileira e conseguimos. Foi um sucesso total. (Josina. Rio de Janeiro, Maio, 2019).

Outro emprego dos turbantes (de uso mais recente) tem ocorrido através das divulgações e tutoriais dos sites liderados por mulheres negras - jovens em sua

\footnotetext{
IX Josina Maria da Cunha. Ativista do movimento de mulheres negras do Rio de Janeiro, desde os anos Integrante do Fórum Estadual de Mulheres Negras e Ebome de Oxum. Entrevista concedida em maio de 2019.
}

Revista Zona Franca- Centro de estudios interdisciplinario sobre las mujeres (CEIM)- Maestría poder y sociedad desde la problemática de género (MG), Rosario, Argentina. ISSN, 2545-6504 http://zonafranca.unr.edu.ar/index.php/ZonaFrancal Numero 27 (2019). 
maioria- que pelos de seus blogs e vlogs os tem utilizado como construção identitária. Nesta ambiência, este adorno passa a lidar com duas apropriações opostas entre si: uma delas, a aquisição e uso pela indústria temporária da moda. $\mathrm{O}$ que permite e estimula a que mulheres de diferentes pertencimentos raciais os enverguem nas ruas ou ambientes sociais os mais variados. Quando tal ocorre, toda uma significância político cultural de seu uso se esvai. E o adorno passa a ser utilizado como acessório a ser imediatamente descartado no momento em que o mercado da moda, assim o determine.

Outro uso, em contraposição, é a construção, por parte dos movimentos sociais negros, deste adorno - o turbante - como locus de representação político cultural e como tal, portador de uma identidade que o conecta imediatamente com os aspectos da africanidade e sua reapropriação, em terras brasileiras e portenhas. Tal escolha remete - a quem o porta - à uma história construída desde a África subsaariana. Logo, estreitamente contribuidora de um reposicionamento positivo de corpos negros em diáspora, como nos diz Josina Maria:

Aí eu comecei dentro do movimento a trabalhar a questão da identidade, através da estética negra voltada para as meninas, para as mulheres... através da indumentária, através do fortalecimento, através da busca da identidade desta mulher negra. Não basta você usar uma roupa, não basta você botar uma pano na cabeça. Você tem que estar imbuída desta identidade: o que eu sou? de onde eu venho? O que eu quero para mim? como é o meu corpo? Aí, eu comecei a desenvolver várias oficinas buscando desenvolver a identidade dessa mulher negra... Como eu trabalho com indumentária, a gente começa a trabalhar a questão do turbante... Como é que a gente pode através de um símbolo estético, mostrar a nossa força, a nossa identidade (Josina. Rio de Janeiro, Maio, 2019).

Se vimos em Le Breton (2006) que o corpo carrega um si uma mensagem, este quando adornado, pode potencializar e ampliar seu discurso. Assim, um corpo negro portanto um turbante - para além da moda, que pode ser a razão

Revista Zona Franca- Centro de estudios interdisciplinario sobre las mujeres (CEIM)- Maestría poder y sociedad desde la problemática de género (MG), Rosario, Argentina. ISSN, 2545-6504 http://zonafranca.unr.edu.ar/index.php/ZonaFrancal Numero 27 (2019). 
única de seu uso- permitirá uma representação identitária de afirmação do ser negro. Mesmo que este não seja a intenção primeira do uso. Da mesmo forma, quando dialogamos com Ellen Roach, Mary e Eicher, Joanne Bubolz (2011) os adornos também trazem em si, uma carga de significados que podem ser politicamente empreendidos, como no caso das mulheres negras no Peru, durante a marcah de 8 de março de 2019:

Poco antes de empezar la marcha, la Colectiva Presencia y Palabra Mujeres Afroperuanas (PyP) se abrió paso a un ritmo fuerte y vibrante, recibiendo el aplauso de las organizaciones ya instaladas. Casi 50 mujeres afroperuanas ingresaron tocando tambores, cajitas y quijadas de burro, mientras arengaban y bailaban con encendidas camisetas amarillas con la frase "Las vidas de las mujeres negras importan" $\mathrm{x}$.

A frase "a vida das mulheres negras importa", estampada nas camisetas das ativistas negras na marcha do 8 de março, no Peru, as coloca em conexão diaspórica com outras mulheres negras, nas Américas. Ao mesmo tempo, o som dos instrumentos tocados em ritmos das percussões ouvidas em momentos culturais afro peruano, afro brasileiro ou afro argentino as coloca todas em conexão om as fortes influências das religiões de matriz africanas, ainda que seu nome não haja sido elencado.

\section{Pensares conclusivos}

Alguns trabalhos vêm se dedicando a evidenciar questões referentes a gênero e raça de forma interseccional a partir de enfoques que tratam dos efeitos do racismo, sexismo e demais opressões, bem como, as inúmeras estratégias de superação a partir do protagonismo das mulheres negras. Estudos já realizados na área de gênero e ciência trazem como contribuição as reflexões sobre várias das facetas em que gênero opera como marcador primordial na posição social ocupada pelas mulheres.

$x \quad$ Fonte: https://www.mujeresdelsur-afm.org/peru-america-latina-va-a-ser-negra-y-feminista. Acessado em maio, 2019

Revista Zona Franca- Centro de estudios interdisciplinario sobre las mujeres (CEIM)- Maestría poder y sociedad desde la problemática de género (MG), Rosario, Argentina. ISSN, 2545-6504 http://zonafranca.unr.edu.ar/index.php/ZonaFrancal Numero 27 (2019). 
Paralelamente, ao classificar os indivíduos e dividi-los em uma hierarquia que varia de acordo com a tonalidade da cor da pele, o racismo impera em diversas instâncias da sociedade, impedindo que negros e brancos tenham o mesmo acesso às possibilidades circunscritas no mundo moderno. Em consequência, a questão de gênero - quando somada à raça - pode significar as maiores dificuldades para os sujeitos sociais. Assim, as mulheres negras seriam mais vitimadas na sociedade, embora, os movimentos sociais, por elas liderados, como veremos a seguir venha apresentado estratégias diversas de superar estas mazelas.

Mulheres negras peruanas, brasileiras e argentinas buscaram nas representações de África e ou de diáspora, o seu lugar de referência e visibilidade nas marchas de $8 \mathrm{M}$ em seus respectivos países, em 2019. E nestas, os símbolos que remetem à diáspora africana se fazem fortemente representados. Se concordarmos - com os autores aqui estudados- que o corpo e os adorno tem significados que dialogam diretamente com o grupo social circundante, então, o turbante, quando envolvendo uma cabeça negra ultrapassa o sentido do tecido e passa a comunicar-se positivamente contra o racismo.

Assim, mesmo num ambiente "amigo": o dos feminismos e movimentos sociais, a admiração, surpresa e exotização se expressava nos muitos celulares e câmaras apontados, sem pedir autorização ou licença para o registro. Tais atitudes produzem, ainda mais contundentemente, a indignação e insurgência daquelas ativistas, durante todo o cortejo. São corpos (re) afirmados e sonoros numa ambiência de desafirmação e silenciamento. Todas possibilitadas pelo quadro de relações raciais nos três países, como vimos rapidamente aqui.

Melluci (1996) nos fala de uma rede oculta (Hidden Network) dos movimentos sociais que vem a público em diferentes situações e com objetivos específicos. Podemos ver as marchas, como expressão manifesta do que nos diz o autor, notadamente no âmbito de sua representação por mulheres negras

Revista Zona Franca- Centro de estudios interdisciplinario sobre las mujeres (CEIM)- Maestría poder y sociedad desde la problemática de género (MG), Rosario, Argentina. ISSN, 2545-6504 http://zonafranca.unr.edu.ar/index.php/ZonaFranca| Numero 27 (2019). 
organizadas. Por conseguinte, os turbantes (no Rio de Janeiro e na Argentina) ou as camisetas amarelas, portando palavras de ordem e os panos - nas mãos- com desenhos de búzios (em Lima), ao serem utilizados nas marchas, atuam como anúncio de oposição das mulheres negras em diáspora, contra o racismo e o sexismo.

\section{Bibliografia}

AGUIRRE, Carlos (2000). Lo africano en la cultura criolla, Editora Fondo Editorial del Congreso del Perú.

ANDREWS, George Reid (2007). América Afro-Latina (1800-2000). Trad. Magda Lopes, São Carlos, SP: EdUFSCar.

CARNEIRO, Sueli (2003), "Enegrecer o feminismo", Estudos avançados, No 17.

DREWAL, Hj (1979). "Pageantry and power in Yoruba costuming", The fabrics of culture: the anthropology of clothing.

ELLEN ROACH, Mary e EICHER, Joanne Bubolz (2011). Language of Personal Adornment. In: The fabrics of culture. The Anthropology of clothing and adornment.

FRIGERIO, Alejandro, LAMBORGHINI, Eva, Criando um movimento negro em um país "branco": ativismo político e cultural afro na Argentina. 2009 Afro-Ásia. Disponível em: shttp://www.redalyc.org/articulo.oa?id=77019346006> ISSN 00020591 Acesso em 10 de maio de 2018.

GONZALES, Lélia (1988). "Por un feminismo afrolatinoamericano", na Revista Isis International. vol. IX, Santiago, junio, Chile, MUDAR/DAWN, p. 133141.

GUIMARÃES, Antônio Sérgio Alfredo (1999). "Raça e os estudos de relações raciais no Brasil" na Novos Estudos, $N^{\circ} 54$.

LE BRETON, D. "A Sociologia do corpo". (2006). Editora Vozes; 2006. 
MAULEÓN, Cecília Olea (1998). "Preguntar no ofende: Adónde están las mujeres negras?" In: Encuentros, (des)encuentros y búsquedas: el movimento feminista en América Latina. Centro de la Mujer Flora Tristan.Lima, Peru.

MUNANGA, Kabenguele (2006). "Algumas considerações sobre raça, ação afirmativa e identidade negra no Brasil: fundamentos antropológicos", Revista USP.

REVISTA Isis Internacional (1986), vol. V de junho.

ZEGARRA, Monica Carrillo (2010). Insumissas - Racimo, sexismo, organización, política y desarrollo de la Mujer Afrodescendiente. Cedet Editorial, Lima Perú

Revista Zona Franca- Centro de estudios interdisciplinario sobre las mujeres (CEIM)- Maestría poder y sociedad desde la problemática de género (MG), Rosario, Argentina. ISSN, 2545-6504 http://zonafranca.unr.edu.ar/index.php/ZonaFrancal Numero 27 (2019). 